\author{
Dhiman Adhikari, Sandeep Kumar \\ Kar*, Rajat Choudhuri, Anupam \\ Goswami and Chaitali Sen Dasgupta \\ Department of Anaesthesiology and Cardiac \\ Anesthesiology, Institute of Postgraduate Medical \\ Education andResearch, 244 A.J.C. Bose Road, \\ Kolkata, India-700020 \\ Dates: Received: 12 July, 2014; Accepted: 05 \\ September, 2014; Published: 08 September, 2014 \\ *Corresponding author: Sandeep Kumar Kar, \\ Department of Anaesthesiology and Cardiac \\ Anesthesiology, Institute of Postgraduate Medical \\ Education and Research, 244 A.J.C. Bose Road, \\ Kolkata, India-700020, E-mail: sndpkar@yahoo.co.in \\ www.peertechz.com
}

ISSN: 2455-3484

Keywords: Smoking cessation; Varenicline; Bupropion; Nicotine replacement therapy and counseling

\section{Review Article \\ A Discussion about Modalities of Smoking Cessation in Perioperative Phase for Addicts: A Review Article}

\section{Introduction}

Tobacco, in the form of cigarette smoking is the leading preventable cause of mortality and it is responsible for nearly six million deaths worldwide [1,2]. Nearly $35 \%$ of adults in India use some form of tobacco. Smoking related mortality in India is among the highest in the world and about 930,000 adult deaths in India were due to smoking alone in 2010 [3,4]. Excess deaths among smokers, as compared to non smokers were chiefly from tuberculosis and respiratory, cardiovascular or malignant diseases [3]. It is estimated that 8.3 million cases of coronary artery disease and chronic obstructive airway diseases are also attributable to tobacco each year [5]. The three major causes of smoking-related mortality are atherosclerotic cardiovascular disease, lung cancer, and chronic obstructive pulmonary disease (COPD) [2].

Complications related to anaesthesia and surgery are important considerations forpatients addicted to smoking this results in increased morbidity, extended hospital stay and recovery. Five to ten per cent of a population may annually undergo surgeryand anaesthesia. Pulmonary or cardiovascular complications occurin up to $10 \%$ of the cases [6], with people who smoke having a considerably increased risk of intra- and postoperative complications [7]. In a retrospective study smokerswere found to have three- to six-fold increased risk of intraoperative pulmonary complications. Patients with chronic heart or lung disease have a two- to five-fold increased risk of perioperative complications [8].
Smoking cessation prior to or in the perioperative phase has been traditionally advised to be for 6 weeks but such an endeavour may have unwanted consequences because of withdrawal symptoms. Hence it is necessary that smoking cessation is achieved with minimal consequences so that the operative procedure can be conducted with minimal adversities.

This article shall be targeted to enlighten the possible ways to aid smoking cessation but with least withdrawal signs.

\section{Discussion}

It is recognized that the perioperative period represents a "teachable moment" when many smokers quit or attempt to quit smoking, sometimes permanently $[9,10]$. The opportunity for clinicians to actively participate in this phase should be seized and patients instructed on the means available to them to quit smoking prior to their surgery.

These times of exposure to general anesthesia and/or surgery offer a window of opportunity for smoking cessation intervention by a healthcare provider or other individual. This person can be the surgeon, the anesthesiologist or the nurse who should encourage the patient to stop smoking temporarily before the surgery or, preferably permanently. The intervention canbe carried out at the surgical clinic or anesthetic pre-admission testing clinic, via phone calls by nurses or health care workers, or in a letter indicating the risks of postoperative complications caused by continued smoking. Recent evidence shows 
that the earlier the intervention before surgery, the more effective it is in reducing the postoperative complications and maintaining abstinence. Cigarette smoking is the single most important risk factor for the development of COPD and death caused by lung disease. The effects of smokingon different organ systems are described in table 1. It recommends systematically identifying all tobacco users who come in contact with the health care system to urge and help them to quit smoking.

The American Society of Anesthesiologists also has a Stop Smoking Initiative and provides resources to help practitioners encourage smoking cessation among smokers, predictive factors for the development of pulmonary complications are a lower diffusing capacity than predicted and a smoking history of more than 60 pack-years. Those who have smoked more than 60 pack-years have double the risk of any pulmonary complication and triple the risk of pneumonia compared with those who have smoked less than 60 packyears. Smoking cessation causes the symptoms of chronic bronchitis to diminish or disappear and eliminates the accelerated loss of lung function observed in those who continue to smoke. Anesthesiologists who practice pain medicine also have the opportunity to encourage smoking cessation in their patients. Among adults with chronic pain, smoking is associated with higher levels of pain, greater levels of depression and anxiety, worse physical functioning, and use of larger amounts of prescription opioids. However, it is not known how smoking cessation might affect pain symptoms.

\section{Beneficial effects of smoking cessation}

The adverse effects of carbon monoxideon oxygen-carrying capacity and of nicotine on the cardiovascular system are short-lived. The elimination half-life of carbon monoxide is approximately 4 to 6 hours when breathing room air. Within 12 hours after cessation of smoking the partial pressure of oxygen in arterial blood (Pao2) at which hemoglobin is $50 \%$ saturated with oxygen (P50) increases from 22.9 to $26.4 \mathrm{~mm} \mathrm{Hg}$, and the plasma levels of carboxyhemoglobin

Table 1: Effects of smoking on different organ systems (in relation to anaesthesia and surgery) [12].

\begin{tabular}{|l|l|}
\hline \multirow{2}{*}{$\begin{array}{l}\text { CARDIAC EFFECTS } \\
\text { OF SMOKING }\end{array}$} & $\begin{array}{l}\text { Smoking is a risk factor for development of } \\
\text { cardiovascular disease. } \\
\text { Carbon monoxide decreases oxygen delivery and } \\
\text { increases myocardial work. } \\
\text { Smoking releases catecholamines and causes } \\
\text { coronary vasoconstriction. } \\
\text { Smoking decreases exercise capacity. }\end{array}$ \\
\hline RESPIRATORY & $\begin{array}{l}\text { Smoking is the major risk factor for development of } \\
\text { chronic pulmonary disease. } \\
\text { EFFECTS OF }\end{array}$ \\
SMOKING & $\begin{array}{l}\text { Smoking decreases mucociliary activity. } \\
\text { Smoking results in hyper reactive airways. } \\
\text { Smoking decreases pulmonary immune function. }\end{array}$ \\
\hline OTHER ORGAN & $\begin{array}{l}\text { Smoking impairs wound healing. } \\
\text { Smoking is a major risk factor for many types of } \\
\text { malignancy. } \\
\text { The number of cigarettes smoked daily is associated } \\
\text { with an increased risk for developing type } 2 \text { diabetes } \\
\text { mellitus over the long-term. } \\
\text { Smoking is associated with an increased risk of } \\
\text { several reproductive disorders. }\end{array}$ \\
\hline
\end{tabular}

decrease from $6.5 \%$ to approximately $1 \%$. Carbon monoxide may have negative inotropic effects. Despite the favorable effects on plasma carboxyhemoglobin concentration, short term abstinence from cigarettes has not been proven to decrease the incidence of postoperative pulmonary complications. The sympathomimetic effects of nicotineon the heart are transient; lasting only 20 to 30 minutes. Cigarette smoking causes mucus hypersecretion, impairment of mucociliary transport, and narrowing of small airways. In contrast to the rapid favorable effect of short-term abstinence from smoking on carboxyhemoglobin concentrations, improved ciliary and small airway function and decreased sputum production occur slowly over a period of 4-6 weeks after smoking cessation. Cigarette smoking may interfere with normal immune responses and could interfere with the ability of smokers to respond to pulmonary infection following anesthesia and surgery. A decrease in postoperative pulmonary complications resulting from smoking cessation is thought to be related to the physiologic improvement in ciliary action, macrophage activity, and small airway function, as well as a decrease in sputum production. However, these changes take weeks to month's tooccur. Return of normal immune function requires at least6 weeks of abstinence from smoking [11]. Some components of cigarette smoke stimulate hepatic enzymes. As with immune responses, it may take 6 weeks or longer for hepatic enzyme activity to return to normal following cessation of smoking. The optimal timing of smoking cessation before surgery to reduce postoperative pulmonary complications remains unclear, but many suggest it to be around 4 to 8 weeks. Smokers scheduled for surgery in less than 4 weeks should be advised to quit and should be offered effective interventions, including behavioral support and pharmacotherapy, to help achieve this goal [11].

\section{Risks of smoking cessation}

Although the risks of smoking cessation are substantially outweighed by the benefits, these risks are important to address in order to maximize the likelihood that a patient will successfully quit smoking.

Nicotine withdrawal syndrome - Nicotine is a potent psychoactive drug that causes physical dependence and tolerance [12]. In the absence of nicotine, a smoker develops urges for cigarette and symptoms of the nicotine withdrawal syndrome. Symptoms generally peak in the first three days and subside over the next three to four weeks, but smokers' cravings for cigarettes may persist for months to years. Nicotine withdrawal symptoms includes increased appetite or weight gain, dysphoric or depressed mood, insomnia, irritability, frustration or anger, anxiety, difficulty concentrating and restlessness. These factors should be addressed, so that smokers will know what to expect and how to respond if these symptoms occur.

\section{Modes of smoking cessation}

Non-pharmacological methods: Many smokers try to quit on their own but in the absence of additional support, each quitting attempt will only have a success rate of 4-7 \% [13]. Quitting success tends to be greater in patients having surgery. Advice and encouragement delivered by physicians improves quitting success. Further, this group may be more motivated to quit. The Smoking Cessation Taskforce 
of the American Society of Anesthesiologists developed a simple three-point cessation strategy (A-A-R=Ask, Advise, Refer) that may be used in everyday practice [14]. These are similar to guidelines for Australian General Practice and recommendations of the Australian National Health Preventative Taskforce [15].

$\mathrm{A}=$ Ask. Patients are asked about their smoking status. Asking reinforces the message to the patient that his or her doctor believes the tobacco use is a significant issue.

$\mathrm{A}=$ Advise. Most smokers are aware of the risks that are printed on the packet regarding future cardio-respiratory disease and cancer, yet data show that few have awareness of the specific perioperative risks that smoking poses them. By understanding the benefits of quitting before surgery, the chances of behavioural change prior to surgery may be increased [16].

$\mathrm{R}=$ Refer. An awareness of locally available smoking cessation support and referral of patients significantly improves quit rates. In randomised controlled trials of perioperative quit programs, more intensive interventions produced significantly greater abstinence [17]. General practitioners, pharmacists, counsellors at local community health centres and telephone quitlines may be appropriate referral points. The role of the general physicians and the non-specialized doctors is very important in this aspect. Compared to the provision of self help alone, multi-session counseling delivered via telephone quitlines increased smoking abstinence at 12 months by a significant 25-50 per cent [18]. A Victorian study showed that multi-session Quitline counselling resulted in 24 per cent of participants being abstinent at three months [19].

Cognitive behavioral therapy: Clinicians have screening and intervention modalities that can be used to promote smoking cessation. Both the Agency for Health Care Policy and Research (AHCPR) and the American Psychiatric Association (APA) have set forth similar guidelines to help clinicians target this risk factor in their patients $[20,21]$. All smokers should be asked if they are willing to commit to cessation and if patients are agreeable, the clinician should discuss the various treatment options available.

Hypnotherapy: Some patients have used hypnotherapy as an aid for smoking cessation, especially in attempting to alleviate or lessen the urge to smoke. A meta-analysis of 9 randomized trials of hypnotherapy for smoking cessation was conducted; comparative interventions included hypnotherapy with or without counseling, hypnotherapy with or without group therapy, psychological treatments, and no therapy [22]. The authors concluded that hypnotherapy did not demonstrate greater rates of cessation at 6 months compared with other interventions or with no therapy.

Acupuncture: Many smokers have used acupuncture in an attempt to limit or alleviate nicotine withdrawal symptoms. One study examined the effects of acupuncture on smoking cessation in 46 patients who were followed for 5 years [22]. Enrolled patients had smoked for an average of 23 years, typically smoked 10 to 30 cigarettes/day, agreed not to use any other form of cessation modalities during the 3-week treatment phase, and were willing to quit smoking. A total of 26 patients received acupuncture in specific areas that are thought to correspond to areas of the body affected by smoking, such as the lungs and mouth. The control group consisted of 20 patients who received acupuncture in areas that are not thought to correspond to areas affected by smoking. Patients received treatment twice weekly for 3 weeks. Patients were asked how many cigarettes they smoked, and blood samples were drawn to determine concentrations of cotinine and thiocyanate; this enabled researchers to determine whether patients had smoked in the preceding few weeks. At the 5-year follow-up, 4 patients from the acupuncture group had maintained abstinence compared with 2 patients from the control group.

Pharmacological methods: Tobacco cessation for a current tobacco user (most of whom are dependent) needs an active approach and provision of support for a cessation attempt. Most studies evaluating tobacco cessation interventions recommend a combination of pharmacotherapy with behavioral interventions. Pharmacotherapy has been shown to double or triple quit rates $[23,24]$. There is a limited range of pharmacological options available for tobacco cessation. These broadly include nicotine replacement therapy (NRT) such as nicotine gum, nicotine patch, nicotine spray etc. and non-nicotine therapies such as bupropion, nortriptyline and varenicline. The most commonly used drugs are varenicline and bupropion. The focus of this article is on partial selective nicotine receptor agonist drug varenicline.

\section{Varenicline}

Varenicline (available in the form of varenicline tartrate), is a nicotinic receptor partial agonist-it stimulates nicotine receptors more weakly than nicotine itself does. In this respect it is similar to cytisine and different from the nicotinic antagonists such as bupropion, and nicotine replacement therapies (NRTs) like nicotine patches and nicotine gum. As a partial agonist it both reduces cravings for and decreases the pleasurable effects of cigarettes and other tobacco products. Varenicline is a partial agonist of the $\alpha_{4} \beta_{2}$ subtype of the nicotinic acetylcholine receptor. In addition it acts on $\alpha_{3} \beta_{4}$ and weakly on $\alpha_{3} \beta_{2}$ and $\alpha_{6}$-containing receptors. A full agonism was displayed on $\alpha_{7}$-receptors $[25,26]$. Acting as a partial agonist varenicline binds to, and partially stimulates, the $\alpha_{4} \beta_{2}$ receptor without producing a full effect like nicotine. Thus varenicline does not greatly increase the downstream release of dopamine. Due to its competitive binding on these receptors, varenicline blocks the ability of nicotine to bind and stimulate the mesolimbic dopamine system, akin to the action of buprenorphine in the treatment of opioid addiction [26]. Varenicline also acts as an agonist at 5-HT3 receptors, which may contribute to mood altering effects of varenicline [27].

Most common side effect of varenicline is nausea. Other less common side effects include headache, difficulty sleeping, and abnormal dreams. Rare side effects reported by people taking varenicline compared to placebo include change in taste, vomiting, abdominal pain, flatulence, and constipation. Gastrointestinal side-effects are important factors compromising the compliance of varenicline [28].

Use of varenicline may be associated with serious neuropsychiatric symptoms like self harm and suicidal behaviour. It is unknown whether the psychiatric symptoms are related to the drug or to 
nicotine withdrawal symptoms [29]. As of July 2009, the US Food and Drug Administration requires varenicline to carry a black box warning, the agency's strongest safety warning, due to public reports of side effects including depression, suicidal thoughts, and suicidal actions [30].

There are reports of serious cardiovascular (CV) events with varenicline use. A meta-analysis reported a small but statistically significant rise in serious $\mathrm{CV}$ adverse events, i.e. ischemia, arrhythmia, congestive heart failure, sudden death or CV-related death in subjects receiving varenicline [31]. However reanalysis of the data did not show support for any significant increase in the risk of treatment emergent, CV serious adverse events related to varenicline use [32]. In view of the low absolute increase in risk for serious CV events, compared with the large benefit for smoking cessation, current opinion appears to suggest varenicline may be used in stable CV disease.

Dosage of varenicline- [33]

Day $1-3 \rightarrow 0.5$ mg once daily

Day $4-7 \rightarrow 0.5$ mg twice daily

Day 8-14 $\rightarrow 1 \mathrm{mg}$ twice daily (quit date in this period)

Day 15-12 week's $\rightarrow 1 \mathrm{mg}$ twice daily

The FDA has approved the use of varenicline for up to twelve weeks. If smoking cessation has been achieved it may be continued for another twelve weeks [33]. Varenicline has not been tested in those under 18 year's old or pregnant women and therefore is not recommended for use by these groups. Varenicline is available in India since 2008.

\section{Dosage of bupropion-[34]}

Day $1-3 \rightarrow 150 \mathrm{mg}$ (bupropion SR tablet) once daily

Day 3-12 weeks $\rightarrow 150 \mathrm{mg}$ twice daily (quit date $1-2$ weeks after start of treatment)

\section{Advantages of varenicline over bupropion and NRT}

Varenicline has been found to be more beneficial and cost effective over other agents (namely bupropion and NRT) in a multitude of studies.

In a 2006 randomized controlled trial, after one year the rate of continuous abstinence was $10 \%$ for placebo, $15 \%$ for bupropion and $23 \%$ for varenicline [35]. In a 2009 meta-analysis of 101 studies funded by Pfizer, varenicline was found to be more effective than bupropion (odds ratio 1.40) and NRTs (odds ratio 1.56) [36]. A Cochrane systematic review concluded that varenicline improved the likelihood of successfully quitting smoking by two- to three-fold relative to pharmacologically unassisted attempts. Varenicline was more efficacious than bupropion in this regard but not statistically superior to NRT [37].

In a placebo controlled randomized clinical trial Cinciripini et al. [38] showed that for community sample, varenicline exerts a robust and favorable effect compared to bupropion, on smoking cessation relative to placebo and may have a favorable (suppressive) effect on symptoms of depression and other affective measures, with no clear unfavorable effect on neuropsychiatric adverse events.

Brose et al. [39] showed that varenicline is marginally more effective than combination NRT for smoking cessation. Continuous or sustained abstinence at 6 months or longer for varenicline at standard dosage versus placebo showed a RR of 2.27 ( $95 \%$ confidence interval [CI]: 2.02-2.55) [40] and odds ratio (OR) of 2.88 (95\% CI: 2.40-3.47) [41]. A low or variable dose of varenicline was twice more effective than placebo. Varenicline was found to be slightly superior to single forms of NRT in two trials, with an RR of 1.13 (95\% CI: 0.94$1.35 ; 2$ trials, 778 people) but was not more effective than combination NRT $[37,40]$. In a recent study where minimal professional support was offered in routine care, the odds ratio of being abstinent was 1.76 (CI: 1.23-2.53) with varenicline compared to NRT [41].

A recent study on effectiveness of varenicline among smokers from Asian populations (China, India, Philippines and Korea) showed that overall $46.4 \%$ of people successfully quit smoking by the end of 12 week [42].

British Medical Journal published an article in 2012 that reported on a national cohort study in Denmark with 35,852 smokers using either bupropion or varenicline. This study found no significant differences in the rates of cardiovascular events by the drug varenicline [43].

Varenicline is also more cost effective compared to other agents in respect with quality adjusted life year. Studies in Europe showed that a total of 12 weeks of varenicline followed by a further 12 -week course for successful quitters is a highly cost-effective alternative compared with currently available smoking cessation options [44].

\section{Conclusion}

In the present era, nicotine receptor partial agonists represent the most promising pharmacotherapeutic agents for smoking cessation. The importance of smoking cessation is more relevant when a patient is posted for surgery where abstinence improves both intraoperative and postoperative outcome. There are several trials establishing the superior effectiveness and safety of varenicline in tobacco, particularly smoking cessation. However more research work is needed to acknowledge the cardiovascular and psychiatric side effects of the drug.

\section{Acknowledgement}

We are utterly grateful to the members of Department of Anaesthesiology and Critical Care, Institute of Postgraduate Medical Education and Research, Kolkata for their constant support and guidance.

\section{References}

1. World Health Organization Report on the Global Tobacco Epidemic, 2011 Warning about the dangers of tobacco. World Health Organization, Geneva 2011. http://whqlibdoc.who.int/publications/2011/9789240687813_eng.pdf.

2. Centers for Disease Control and Prevention (CDC) (2008) Smokingattributable mortality, years of potential life lost, and productivity lossesUnited States, 2000-2004. MMWR Morb Mortal Wkly Rep.

3. Jha P, Jacob B, Gajalakshmi V, Gupta PC, Dhingra N, et al. (2008) A 
nationally representative case-control study of smoking and death in India. N Engl J Med 358: 1137-1147.

4. Gajalakshmi V, Peto R, Kanaka TS, Jha P (2003) Smoking and mortality from tuberculosis and other diseases in India: Retrospective study of 43000 adult male deaths and 35000 controls. Lancet 362: 507-515.

5. Murthy P, Saddichha S (2010) Tobacco cessation services in India: Recent developments and the need for expansion. Ind J Cancer 47: 69-74.

6. Pedersen T (1994) Complications and death following anaesthesia. A prospective study with special reference to the influence of patient-, anaesthesia-, and surgery-related risk factors. Dan Med Bull 4: 319-331.

7. Bluman LG, Mosca L, Newman N, Simon DG (1998) Preoperative smoking habits and portoperative pulmonary complications. Chest 113: 883-889.

8. Akrawi W, Benumof JL (1997) A pathophysiological basis for informed preoperative smoking cessation counseling. J Cardiothorac Vasc Anesth 11: $629-640$.

9. Webb AR, Robertson N, Sparrow M (2013) Smokers know little of their increased surgical risks and may quit on surgical advice. ANZ J Surg.

10. Shi Y, Warner DO (2010) Surgery as a teachable moment for smoking cessation. Anesthesiology 112: 102-107.

11. Kurup V. Respiratory Disease (2009) Hines LR, Marschall KE (ed): Stoelting's Anaesthesia and Co-Existing Disease. Philadelphia, Churchill Livingstone 161-198.

12. Rigotti NA (2002) Treatment of tobacco use and dependence. N Engl J Med 346: 506.

13. Simon JA (2011) Smoking cessation interventions: A primer for physicians: Comment on "Use of varenicline for 4 weeks before quitting smoking". Arch Intern Med 171: 777-778.

14. Warner DO (2009) Feasibility of tobacco interventions in anesthesiology practices: A pilot study. Anesthesiology 110: 1223-1228.

15. Zwar N, Richmond R, Borland R, Peters M (2011) Supporting smoking cessation: A guide for health professionals. Melbourne: Royal Australian College of General Practitioners.

16. Webb AR, Robertson N, Sparrow M (2013) Smokers know little of their increased surgical risks and may quit on surgical advice. ANZ J Surg 2013.

17. Thomsen T, Villebro N, Moller AM (2014) Interventions for preoperative smoking cessation. Cochrane Database Syst Rev 7: CD002294.

18. Stead LF, Perera R, Lancaster T (2006) Telephone counselling for smoking cessation. Cochrane Database Syst Rev 3: CD002850.

19. Borland R, Segan CJ, Livingston PM, Owen N (2001) The effectiveness of callback counselling for smoking cessation: A randomized trial. Addiction 96 : 881-889.

20. Sackey JA (2007) Behavioral approach to smoking cessation. In: Up To Date

21. (1996) Practice guideline for the treatment of patients with nicotine dependence. American Psychiatric Association. Am J Psychiatry 153: 1-31.

22. Abbott N, Stead L, White A (1998) Hypnotherapy for smoking cessation. Cochrane Database Syst Rev 2: CD001008.

23. Faessel HM, Obach RS, Rollema H, Ravva P, Williams KE, et al. (2010) A review of the clinical pharmacokinetics and pharmacodynamics of varenicline for smoking cessation. Clin Pharmacokinet 49: 799-816.

24. Gunnell D, Irvine D, Wise L, Davies C, Martin RM (2009) Varenicline and suicidal behaviour: A cohort study based on data from the General Practice Research Database. BMJ 339: 3805.

25. MihalakKB, Carroll FI, Luetje CW (2006) Varenicline is a partial agonist at $\alpha 4 \beta 2$ and a full agonist at $\alpha 7$ neuronal nicotinic receptors. Mol Pharmacol 70 : 801-805.
26. Rollema H, Chambers LK, Coe JW (2007) Pharmacological profile of the $\alpha 4 \beta 2$ nicotinic acetylcholine receptor partial agonist varenicline, an effective smoking cessation aid. Neuropharmacology 52: 985-994.

27. MineurYS, Picciotto MR (2010) Nicotine receptors and depression: revisiting and revising the cholinergic hypothesis. Trends Pharmacol Sci 31: 580-586.

28. Leung LK, Patafio FM, Rosser WW (2011) Gastrointestinal adverse effects of varenicline at maintenance dose: a meta-analysis. BMC clinical pharmacology 11: 15

29. Early Communication About an Ongoing Safety Review: Varenicline (marketed as Chantix). United States Food and Drug Administration. November 20, 2007.

30. FDA (2009) Public Health Advisory: FDA Requires New Boxed Warnings for the Smoking Cessation Drugs Chantix and Zyban.

31. Singh S, Loke YK, Spangler JG, Furberg CD (2011) Risk of serious adverse cardiovascular events associated with varenicline: A systematic review and meta-analysis. CMAJ 183: 1359-1366.

32. Prochaska JJ, Hilton JF (2012) Risk of cardiovascular serious adverse events associated with varenicline use for tobacco cessation: Systematic review and meta-analysis. BMJ 344: e2856.

33. U.S. Food and Drug Administration (2006) FDA Approves Novel Medication for Smoking Cessation.

34. http://www.drugs.com/dosage/bupropion.html

35. Jorenby DE, Hays JT, Rigotti NA, Azoulay S, Watsky EJ, et al. (2006) Efficacy of varenicline, ana4 $\beta 2$ nicotinic acetylcholine receptor partial agonist, vs placebo or sustained-release bupropion for smoking cessation: a randomized controlled trial. JAMA 296: 56-63.

36. Mills EJ, Wu P, Spurden D, Ebbert JO, Wilson K (2009) Efficacy of pharmacotherapies for short-term smoking abstinance: a systematic review and meta-analysis. Harm Reduct J 6: 25

37. Cahill K, Stead LF, Lancaster T (2012) Nicotine receptor partial agonists for smoking cessation. Cochrane Database Syst Rev 4: CD006103.

38. Cinciripini PM, Robinson JD, Karam-Hage M, Minnix JA (2013) Effects of varenicline and bupropion sustained-release use plus intensive smoking cessation counseling on prolonged abstinence from smoking and on depression, negative affect, and other symptoms of nicotine withdrawal. JAMA Psychiatry 70: 522-533.

39. Brose LS, West R, Stapleton JA (2013) Comparison of the effectiveness of varenicline and combination nicotine replacement therapy for smoking cessation in clinical practice. Mayo Clin Proc 88: 226-233.

40. Cahill K, Stead LF, Lancaster T (2011) Nicotine receptor partial agonists for smoking cessation. Cochrane Database Syst Rev 2: CD006103.

41. Kralikova E, Kmetova A, Stepankova L, Zvolska K, Davis R, et al. (2013) Fifty-two-week continuous abstinence rates of smokers being treated with varenicline versus nicotine replacement therapy. Addiction 108: 1497-1502.

42. Wang C, Cho B, Xiao D, Wajsbrot D, Park PW (2013) Effectiveness and safety of varenicline as an aid to smoking cessation: Results of an inter-Asian observational study in real-world clinical practice. Int J Clin Pract 67: 469-476.

43. Svanstrom H, Pasternak B (2012) Use of varenicline for smoking cessation and risk of serious cardiovascular events: nationwide cohort study. BMJ 345.

44. Bolin K, Mork AC, Wilson K (2009) Smoking-cessation therapy using varenicline: the cost-utility of an additional 12-week course of varenicline for the maintenance of smoking abstinence. J Eval Clin Pract 15: 478-485.

45. Rastogi T, Jha P, Reddy KS, Prabhakaran D, Spiegelman D, et al. (2005) Bidi and cigarette smoking and risk of acute myocardial infarction among males in urban India. Tob Control 14: 356-358.

Copyright: (c) 2014 Adhikari D. This is an open-access article distributed under the terms of the Creative Commons Attribution License, which permits unrestricted use, distribution, and reproduction in any medium, provided the original author and source are credited. 